\title{
Monitor the Adsorption of Bromine Vapor on Zeolitic- Imidazolate Framework-8 Film by an Electrodeless Quartz Crystal Microbalance in Overtone
}

\author{
Dazhong Shen ${ }^{*}$, Lingqiang Kong, Xiaolong Ma, Xuxiang Wang, Honghai Wang, Qi Kang ${ }^{*}$ \\ College of Chemistry, Chemical Engineering and Materials Science, Collaborative Innovation Center \\ of Functionalized Probes for Chemical Imaging in Universities of Shandong, Key Laboratory of \\ Molecular and Nano Probes, Ministry of Education, Shandong Provincial Key Laboratory of Clean \\ Production of Fine Chemicals, Shandong Normal University, Jinan 250014, P. R. China. \\ *E-mail: dzshen@sdnu.edu.cn; qikang@sdu.edu.cn
}

doi: $10.20964 / 110352$

Received: 10 January 2016 / Accepted: 28 January 2016 / Published: 1 April 2016

\begin{abstract}
In this work, the overtone response of an electrodeless quartz crystal microbalance (EL-QCM) in gaseous phase was investigated by an impedance analysis method. It was shown that the influence of the electrode gap on the resonant frequency reduces with increasing overtone number. Although reduced with increasing overtone, the effective quality factor is still high enough even at 7 th overtone $\left(3.8 \pm 10^{4}\right)$ for the stable resonance of the EL-QCM. The EL-QCM was applied to monitor the adsorption processes related to corrosive gas, modeling by bromine vapor onto zeolitic-imidazolate framework-8 (ZIF-8) film. It was shown that the 2-methylimidazole unit in ZIF-8 plays important role for $\mathrm{Br}_{2}$ adsorption, preponderating in chemical adsorption. The adsorption kinetic data are in agreement with the pseudo-second-order model. The adsorption isotherms are well fitted by the Langmuir model with the saturation adsorption capacity of $3241 \mathrm{mg} / \mathrm{g}$ on ZIF-8 with thickness of $0.699 \mu \mathrm{m}\left(25^{\circ} \mathrm{C}\right)$. The correlations of the frequency shifts at the overtone $(\mathrm{n}=1,3,5)$ can be employed to judge the rigidity of the film in an adsorption process.
\end{abstract}

Keywords: Quartz crystal microbalance; Electrodeless; Overtone response; Bromine adsorption; Zeolitic-imidazolate framework

\section{$\underline{\text { FULL TEXT }}$}

(C) 2016 The Authors. Published by ESG (www.electrochemsci.org). This article is an open access article distributed under the terms and conditions of the Creative Commons Attribution license (http://creativecommons.org/licenses/by/4.0/). 